\title{
Automedicação: uma abordagem qualitativa de suas motivações
}

\author{
Self-medication: a qualitative approach of its motivations
}

Janeth de O liveira Silva Naves ${ }^{1}$

Lia Lusitana Cardozo de Castro ${ }^{2}$

ChristineM aria Soares de Carvalho ${ }^{3}$

Edgar M erchán-Hamann ${ }^{4}$

${ }^{1}$ Curso de Ciências

Farmacêuticas,

Universidade de Brasília.

Campus Darcy Ribeiro, Asa

Norte. 70910-900 Braślia

DF.janethnaves@unb.br

${ }^{2}$ Pós-graduação em

Ciências da Saúde,

Universidade de Brasília.

${ }^{3}$ Curso de Letras,

Universidade Católica de

Brasília.

${ }^{4}$ Departamento deSaúde

Coletiva, Universidade de

Brasília.
Abstract A qualitative research was realized to verify the occurrence and motivations for selfmedication and the quality of the information rendered by pharmacies. We conducted 3 focus groupswith 25 patients of a referencepublic health service for STD treatment in Brasília, Brazil. We used the critical discourse analysis to interpret the data obtained during interviews. The analysis revealed that self-medication was a common practice among participants, motivated mainly by discontentment with the long waiting period and the quality of the public health services. Other motivations included: previous experience with medications, advice from friends and family members and the search for an anonymous service provided at pharmacies due to embarrassment and inadequate care environment at health care services. Care provided at pharmacies was also considered unsatisfactory. Viewed essentially as a commercial establishment, pharmacies have become, yet, an easy accessiblealternative. M ost of participants perceived the pharmacists as ordinary employees seeking only to increase profits. The results suggest a need to improve access to health care services, as well as to render it more humane. Community pharmacies should to be turned into health establishments to participate in health education and orientation for rational drugs use.

Key words Self-medication, Focus groups, Discourse analysis, Pharmacies
Resumo A automedicação éuma prática comum que pode retardar o diagnóstico e cura e contribuir para a manutenção da cadeia de transmissão de doenças. Realizou-se pesquisa qualitativa para investigar a ocorrência da automedicação, suas motivações ea qualidade do atendimento em farmácias. 0 estudo realizou três grupos focais em um serviço de referência para o tratamento de DST em Brasília (DF). A análise de discurso crítica revelou que a automedicação era frequente e motivada pela insatisfação com a demora ea baixa quali dade do atendimento nos servi ços de saúde. Outras motivações citadas foram a experiência prévia com medicamentos, o aconselhamento com amigos e familiares e a busca de anonimato nas farmácias.Verificou-se insatisfação com a qualidade do atendimento nas farmácias, vistas como estabel ecimentos comerciais mas quese apre sentam como alternativa defácil acesso. A identidade de farmacêuticos se confunde com a dos vendedoresqueobjetivam o lucro. O bservou-sea centralidade dos medicamentos nas expectativas dos pacientes e nas práticas médicas. Os resultados sugerem a necessidade de melhorar 0 acesso, de resgatar a humanização do atendimento nos serviços de saúde e de transformar as farmácias em estabelecimentos de saúde, di vul gadores de práticas educativas e promotores do uso racional de medicamentos.

Palavras-chave Automedicação, Grupos focais, Análise de discurso, Farmácias 
Introdução

No contexto do sistema de saúde brasileiro, no qual as demandas por atenção à saúde não são plenamente atendidas, a farmácia comunitária, que inclui estabelecimentos públicos e privados de fornecimento de medicamentos, ocupa lugar privilegiado como estabelecimento de saúdemais acessível à população e representa um importante local de busca por atendimento primário de saúde ${ }^{1}$. Nas farmácias brasileiras, a autome dicação e a indicação terapêutica são práticas comuns, mesmo em caso de doenças que necessitam de exames clínicos elaboratoriais para o seu diagnóstico ${ }^{2-4}$. A automedicação é entendida como a sel eção e uso de medicamentos para tratar doenças ou sintomas percebidos pelas pessoas sem a prescrição ou a supervisão de um médico ou dentista 5 .

No Brasil, o setor privado é o principal responsável pelo fornecimento de medicamentos à população brasileira ${ }^{6}$ e comercialização de medicamentos nas farmácias, em geral, está nas mãos de leigos, proprietários e bal conistas. Nesse cenário, devem ser avaliadas todas as vantagens e as desvantagens da automedicação. Entre as desvantagens, está a possibilidade de agravamento de problemas de saúde causados por doenças infecciosas como as doenças sexualmente transmissíveis (DST), já que em muitos casos os usuários quese automedicam não recebem a orientação e o tratamento correto e, apesar da sensação de melhora, se mantêm como elos na cadeia de transmissão dessas doenças ${ }^{1,7}$. 0 tratamento adequado tem como principais objetivosa curae, por conseguinte, a interrupção da cadeia de transmissão ${ }^{8}$.

Em uma sociedade, os hábitos de consumo de medicamentos podem ser afetados positivamente pelas políticas nacionais quando promovem a regulamentação do suprimento e a disponibilização racional de medicamentos essenciais, pressupondo o acesso ao diagnóstico e prescrição por profissionais habilitados. Por outro lado, o consumo pode ser influenciado negativamente pelo acesso sem barreiras e pela promoção e publicidade de medicamentos, que muitas vezes estimulam a utilização desnecessária e irracional. Os governos precisam conhecer as razões easformas de uso irracional de medicamentos; é necessário ter informações específicas para verificar a magnitude desse problema, identificar estratégias emonitorar o impacto das possíveis intervenções?

Além dos interesses econômicos, políticos e fatores estruturais, os padrões de uso de medi- camentos numa sociedade são determinados, também, pelos aspectos interpessoais presentes nas relações entre profissionais e usuários do sistema de saúde e pelas percepções, val ores e crenças que determinam as atitudes individuais com relação à busca de solução para os problemas de saúde ${ }^{10}$. Segundo Lefèvre $^{11}$, existeum nível deação inespecífico dos medicamentos relacionadoscom sua função simbólica; o seu uso confunde-secom a própria solução do problema de saúde e pode conter uma série de expectativas e representações. A procura imediata de saúde através dos medicamentos, frequente em muitas sociedades como a brasileira, sugereum obscurecimento dos determinantes sociais, comportamentais, culturais e psicológicos das doenças.

No contexto de um sistema de saúde muitas vezes insatisfatório, não são percebidos os aspectos contextuais das enfermidades ou seus determinantes e os medicamentos assumem um papel central como ferramenta de resolução do problema. A função simbólica do medicamento pressupõe que a enfermidade seja reduzida a um fenômeno orgânico, que podeser enfrentado por uma mercadoria vista como modo cientificamente válido de se obter um valor altamente desejado, a saúde. A disponibilidade sem barreiras desses produtos ilude os indivíduos e realiza suas expectativas. Esse valor simbólico é conhecido e explorado como estratégia do mercado farmacêutico e garante a acumulação de um dos segmentos mais lucrativos do capital industrial. Em oposição, o uso não simbólico do medicamento implicaria não reduzir a saú de ea doença a fenômenos orgânicos, mas considerá-las fenômenos biopsicossociais. Implicaria, também, reconhecer o medicamento como componente, não obrigatório, de um processo multidimensional de enfrentar situações de desequilíbrio que levam ao aparecimento das doenças e descaracterizá-lo como bem terminal deconsumo, paravêlo como mais um bem intermediário ou complementar na atenção à saúde ${ }^{11}$. É importante ressaltar que a visão simbólica do medicamento permeia não apenas o seu consumo pela população, como também as práticas dos profissionais de saúde.

Considerando-se que a automedicação pode ser influenciada pelas carências e hábitos culturais da sociedade, bem como pela qualidade dos serviços de saúde e pelas práticas dos prescritores, a presente pesquisa utilizou metodologia qualitativa para investigar a ocorrência da automedicação, suas motivações e a qualidade da assistência oferecida nas farmácias. 


\section{Métodos}

A metodologia dos grupos focais foi identificada como a mais adequada para o acesso a relatos e reflexões de pessoas sobre o tema automedicação. Utilizou-se o método proposto por $\mathrm{H}$ ardon et al. ${ }^{9}$, D ebus ${ }^{12}$ eWestphal et al. ${ }^{13}$.

0 grupo focal (GF) é um método qualitativo de pesquisa muito utilizado, que representa uma excelente opção quando se quer obter um conhecimento direto sobre opiniões, crenças e percepções sobre determinado tema ${ }^{13}$. A utilização de métodos qualitativos é recomendada quando se pretende compreender atitudes, motivações e comportamentos das pessoas, para acrescentar sentimento econtextualidadea uma investigação ${ }^{12}$.

O GF compreende a reunião de seis a quinze pessoas desconhecidas anteriormente, queseencontram em um ambiente privativo e não constrangedor e que apresentam al guma característica ou traço em comum, determinada pelos objetivos do estudo ${ }^{13}$. 0 grupo é organizado por um moderador quetem afunção de conduzir e manter a discussão focada, guiada por um roteiro, previamente testado, preparado de acordo com os objetivos da pesquisa. É sua função formular as questões, provocar a discussão e encorajar a livre expressão de todos os membros.

N esta pesquisa, foram realizadas três reuniões de GF em um centro dereferência para tratamento de DST/AIDS da Secretaria de Estado de Saúde do Distrito Federal. Nesse ambiente, julgou-se que os participantes se sentiriam menos constrangidos para falar sobre o tema. Os grupos foram compostos de pacientes e acompanhantes que aguardavam o atendimento médi$c 0$, todos maiores de dezoito anos e com capacidade de compreensão e expressão. As três reuniões tiveram a participação de 25 pessoas, com grupos de dez, oito esetepessoas. Eram dezesseis homens enovemulheres, com idade variando de 22 a 67 anos (média de 34,7). Asreuniões tiveram a duração aproximada de uma hora e meia e geraram três fitas cassete de noventa minutos.

Nas reuniões dos grupos, utilizou-se o método não diretivo de moderação, com perguntas abertas e de livre participação. As reuniões foram guiadas por um roteiro de investigação, que continha, basicamente, três perguntas orientadoras:

. Em algum momento de suas vidas, algum de vocês buscou tratamento para alguma doença sexualmente transmissível em uma farmácia?

- Caso sim, quais foram as motivações que o levaram a essa procura?
- Quais foram as orientações recebidas (qualidade das orientações) nas farmácias?

0 registro foi feito pela gravação das reuniões com o consentimento dos participantes e posterior transcrição literal dos relatos para análise. A transcrição dos relatos gravados utilizou normas segundo $M$ arcuschi ${ }^{14}$, que procura preservar o máximo de fidelidadeentreo diálogo e o texto escrito, observando-se as normas de transcrição de discursos que devem preservar as características das falas com diferentes graus de detalhe, entonação, ênfase, pausa, al tura e ritmo. As gravações das discussões dos GF foram transcritas, na íntegra, pela mesma pesquisadora que atuou como moderadora.

M inayo ${ }^{15}$ apresenta três possibilidades para a etapa de tratamento dos dados empíricos provenientes de relatos resultantes de entrevista e grupos focais: a análise de discurso, a análise de conteúdo ea análise hermenêutica dialética.

Entre as diferentes possibilidades, optou-se pelo método de análise de discurso crítica proposto pelo linguista inglês $\mathrm{N}$ orman Fairclough ${ }^{16}$, por se mostrar de acordo com os objetivos da pesquisa. Para o autor, o discurso é considerado como parteda sociedadeeéentendido como texto, envolvido em uma prática discursiva e situado em uma prática social. 0 método contempla as três dimensões do discurso que são estudadas simultaneamente, seguindo procedimentos analíticos de descrição, na análiselinguística etextual; interpretação, na análise dos processos de produção, distribuição e consumo textual relacionados às estruturas sociais; e explicação, na análise da prática social em três níveis, o econômico, o político (relacionado a questões de poder e ideologia) e o cultural (relacionado a questões devalor eidentidade) ${ }^{16}$. A análiseaqui apresentada privilegiou a dimensão da prática social, utilizando-se, também, outros elementos da pesquisa qualitativa, na qual se procura organizar os relatos dos sujeitos de forma a apreender os significados. A análise de discurso crítica pode ser combinada com a pesquisa qualitativa, pois situa o discurso como parte das práticas sociais no contexto da pesquisa, fornecendo conhecimentos sobre aspectos materiais, relações e processos sociais, instituições sociais, formas de poder, bem como crenças, valores e desejos dos participantes.

Os discursos transcritos foram organizados e, após várias leituras, foram selecionados trechos de relatos num quadro sintético, com citações literais dos participantes, que respondiam às perguntas de pesquisa ou que ilustravam as con- 
clusões. Esse procedimento permitiu a compre ensão, a verificação da frequência de ocorrência de opiniões e a identificação de convergência ou divergência a respeito do tema pesquisado.

O projeto foi aprovado pelo Comitê de Ética em Pesquisa da Secretaria de Estado da Saúde do Distrito Federal. Todos os sujeitos envolvidos na pesquisa assinaram um termo de consentimento atestando que participaram livremente e receberam a garantia de sigilo sobre a sua identidade; para preservar a identidade dos participantes, seus nomes foram mudados nas citações de seus relatos.

\section{Resultados ediscussão}

O número degrupose departicipantes, bem como a duração das entrevistas grupais, foram satisfatórios para os propósitos. 0 guia de temas mostrou ser adequado para responder às questões de pesquisa ea atuação da moderadora e dos observadores foi apropriada, visto que as reuniões transcorreram sem momentos de crise emantendo-se a discussão focada. A participação colaborativa mostrou que os temas faziam parte das experiências vividas pelo grupo e que as pessoas estavam qualificadas para falar sobre 0 assunto. Os relatos nos três grupos mostraram homogeneidade quanto às respostas para as principais questões de pesquisa. No início das reuniões, verificaram-segrandes pausas esilêncios emanifestações mais rápidas e hesitantes. $N$ as perguntas seguintes, com relação à busca de farmácias para tratamento e às motivações que levavam a essa busca, os integrantes dos grupos mostraram-se mais participativos, com tomadas de turnos frequentes, e se manifestavam, com longas participações, expondo suas opiniões. Os discursos mostraram-semaisveementes nos momentos em que os participantes manifestavam sua insatisfação com a qualidade do atendimento no sistema de saúde. Em algumas situações, as participações foram dramáticas, sugerindo sentimentos de insatisfação e sofrimento; em outras, o tom de voz demonstrava mágoa e revolta com relação à desumanização do tratamento recebido.

\section{A procura de tratamento nas farmácias}

Foram constatadas várias ocorrências de respostas afirmativas, principalmente dos participantes do sexo masculino. Alguns assumiram abertamente a busca do tratamento para DST em farmácias, outros atribuíram essa atitude a amigos e outros negaram essa prática. Entre os vários discursos afirmativos, destacam-se os seguintes:

Eu já, já tratei gonorréia na farmácia e vi 0 resultado. (Beto)

Eu conheci uns três ou quatro que fizeram automedicação, né? Teve um que tratou com Tetrex. (Cosme)

Outros relatos afirmam que nunca buscaram tratamento para DST em farmácia e em seguida se contradizem: Eu já procurei, mas não por DST. M as sevocêtem uma doença sexual, cêjá conhece, cê já sabe qual o sintoma. $\mathrm{Na}$ hora que apareceu, cê já sabe qual o remédio que você tem que tomar. Se eu tiver um herpes, eu posso tomar Aciclovir. (Lígia)

Com relação à busca das farmácias para solucionar problemas de saúde, observou-se ainda 0 uso da pressuposição. Nesse tipo de construção, o enunciador faz afirmações e as lança como idéias já estabelecidas ou aceitas, podendo ser consideradas como uma forma de legitimar situações, bem como de manipulação, porque ao serem naturalizadas, tornam-se difíceis de desafiar ${ }^{14}$ : Às vezes, você chega na farmácia e pede, isso é típico do brasileiro, isso é todo mundo, não tem esse negócio. (Flávio)

Eu tenho, éamigos que buscaram, né? 0 mais normal é buscar tratamento, se automedicar. (Cosme)

Foram verificadas, também, respostas negativas com relação à busca de tratamento para DST nas farmácias: Só vou a uma drogaria fazer medicamento se tiver receita. Se não tiver, eu não vou, nunca fui. (José)

M as eu acho que éloucura se procurar farmácia pra doença sexualmente, não é? Depois como é que eu vou sabê se eu tô curado de uma sífilis, de uma gonorréia? Se não tem um exame de sangue? (Souza)

A verificação de várias ocorrências nos discursos afirmando que buscaram tratamento em farmácias demonstrou que essa prática era vivenciada pelos participantes. Esses achados do Distrito Federal confirmam as estimativas da OMS e de outros pesquisadores brasileiros, que apontam as farmácias como importante local de busca para atendimento de saúde, inclusive para o tratamento de problemas de saúde complexos como as DST ${ }^{1,3-6}$.

\section{As motivações para a automedicação}

Sobre as motivações que levam as pessoas a buscarem tratamento nas farmácias, observou- 
se uma grande semelhança nos relatos dos três grupos. M esmo os participantes que afirmaram não buscar tratamento nas farmácias manifestaram sua insatisfação com o atendimento recebido nos serviços de saúde. A maior ocorrência foi de procura justificada pela má qualidade e a demora no atendimento no sistema de saúde, com longo tempo de espera e filas. Em geral, era feita uma associação com a facilidade de acesso ao atendimento nas farmácias. Observa-sea busca de serviços de saúde em situações que exigem solução imediata. 0 grandenúmero de ocorrências, as repetições de palavras e de idéias e o tom de voz alterado ressaltado em letras maiúsculas, comprovam este resultado: É muito difícil pra vocêconseguir no SUS, éTER-RÍ-VEL, VOCÊ NÃO CONSEGUE. Porque cê vai lá no hospital, tá lá lotado de gente. Aí cê chega lá, meu Deus do céu. Tá lá, urgência e emergência. Ah, é emergência? $M$ as esses que tá aqui também é emergência, tão aguardando, então você aguarda também. (Rose)

Às vezes a pessoa se aborrece, de TANTO ficar ali esperando, vai embora. Passa TRÊS M ESES pra receBÊ um resultado? (Fátima)

Outro motivo muito enfatizado éa insatisfação com a qualidade do atendimento na rede pública, classificado por eles como rápido, superficial e impessoal. Os participantes dos grupos relatam que não são examinados, não são tocados, nem sequer são ouvidos: Às vezes, cê quer marcar uma consulta, cê chega, o cara, é pacotão, né? 0 cara nem te examina direito. (Flávio)

Ele não interessa em perguntar, assim, o problema. 0 que você tem, sabe? Ele faz ali uma perguntinha, ali, uma ou duas e já passa a receita. (Celso)

A maioria dos participantes se manifestou insatisfeita com a qualidade das orientações recebidas durante 0 atendimento de saúde, inclusive na rede particular. A sua percepção é que a consulta se resume a ouvir os sintomas e identificar o medicamento mais adequado para aquela queixa. 0 exame clínico, a anamnese detalhada, as orientações educativas não são associadas ao tipo de atendimento que os participantes afirmam receber. Alguns manifestam sua insatisfação com a ausência de esclarecimentos sobre 0 seu problema de saúde ou sobre suas queixas: Eu fui ao médico, foi até um médico particular. Eu fui, ele só olhou ni mim, passou lá um remédio, não procurou fazer um exame, nem nada, né? (Maria)

Eu mesma fui sabê através de livros, que eu tenho da escola ainda. Q ue eu fui procurá, pesquisá. Porque nem médico me disse: "Não, você está com condiloma, papilomavírus". Uai, meu Deus, mas o que éisso? Não foi esclarecido o que é papilomavírus. (Márcia)

Outros reclamam da falta de humanização do atendimento nos serviços de saúde, relatando, até mesmo, maus-tratos: Às vezes, a gente é muito, nos hospitais públicos, nós somos muito maltratados, até mesmo pelos médico. ( $M$ aria)

Então, passar das sete da manhã, praticamente até as três da tarde num hospital, não tem lógica, gente. Fora que ainda tem uns médicos que ainda vem e trata a gente mal. ( $M$ árcia)

Os relatos revelam desânimo e falta de credibilidade no tipo de atendimento que recebem no sistema de saúde. M uitos partici pantes queixamse da baixa resolutividade dos serviços. É referida a necessidade de busca consecutiva dos serviços de saúde que ocorre por problemas organizacionais ou por falta de confiança nos diagnósticos, que muitas vezes representa a perpetuação das suas queixas e do seu sofrimento: Cêtem que ir bem cedo, madrugá aqui, né? Q uando chega na hora, cadê? Não é atendido, não consegue nada. (Fátima)

É muito difícil dá certo. Eu mesmo tô com um problema quetá difícil, num sara dejeito nenhum. (José)

Contrapondo-seà dificuldade deatendimento no sistema de saúde, a farmácia se apresenta como uma opção sem barreiras para 0 acesso, 0 que, somado à insatisfação com os serviços de saúde, coloca as farmácias como locais mais viáveis para a resolução, de forma rápida, dos problemas de saúde: 0 acesso é mais rápido, mais fácil. Cê não tem ficar esperando, não tem que ficar marcando. Se não melhorou, você volta lá e é sempre assim. (Alda)

A pessoa tá precisando ser medicada, vai onde? Às vezes tá agoniada, trabal hando, não pode perder serviço. Ele vai na farmácia. (Beto)

Como a maioria das DST tem manifestações e sintomas que incomodam etrazem sofrimento aos seus portadores, o desejo do paciente é ter alívio imediato: Quem tem doença sexualmente transmissível não pode esperar um tratamento no posto desaúde da região. Porquecêmarca no posto pra daqui uma semana, duas semanas, atéum ano. (Cosme)

Outro motivo alegado para a busca da farmácia é a experiência prévia com um medicamento pela própria pessoa ou a busca por aconselhamento com amigos que já passaram pela mesma experiência. Esse fato é, também, citado por outros pesquisadores que investigaram 0 fenômeno da automedicação no Brasil ${ }^{5,6,17}$, como 
nos relatos a seguir: Eu vou enfrentar fila no hospital? Você chega lá e diz: "Ah, eu tô com dor na coluna, doutô". Ele passa Voltarem. Poi é, eu vou na farmácia, né? (Beto)

$\mathrm{N}$ a verdade, as pessoas quando saem da sua re sidência pra ir até uma farmácia, ele já ouviu alguém falá. "Pô, amigo, que remédio você toma?" "Ah, remédio tal". O amigo já falou que tomou, você resolve o seu problema também. (Gilmar)

Alguns participantes justificam a busca de anonimato no atendimento nas farmácias devido à vergonha de ser um portador de DST ejustificam esseconstrangimento pelo despreparo dos profissionais de saúde no acolhimento de pacientes portadores dessas doenças: A gora quando pessoas que vocêacha que tão ali, sendo treinadas, médicos, psicólogos, não têm capacidade de passar coisas, aí aquilo éfrustrante, né? Q uerendo ou não, às vezes machuca, né? A pessoa às vezes não vai procurá um posto, às vezes por vergonha. (Flávio)

As motivações para busca de tratamento nas farmácias são justificadas, ainda, pelo atendimento da expectativa deobtenção demedicamentos de maneira rápida, satisfazen do a necessidade imediata do usuário: Quando eu procuro uma farmácia é pra comprá. Sempre dou bem com farmácia, não tem nada contra. Ainda mais agora que as farmácias tá sendo assim, mais, é especializada. (José)

As opiniões a respeito das farmácias são contraditórias. No trecho anterior, observa-se satisfação com a qualidade do atendimento recebido nas farmácias. Em outros, a farmácia é identificada como estabelecimento devenda demedicamentos, de fácil acesso, que se apresenta como opção ao atendimento demorado do sistema de saúde que não oferece, na maioria das vezes, orientações satisfatórias, tal qual o verificado nesse sistema.

A qualidade das orientações

recebidas nas farmácias

Se por um lado a farmácia aparece como solução rápida e de fácil acesso, os participantes relatam que o fornecimento de medicamentos nas farmácias não se faz acompanhar de orientações educativas ou preventivas de qualidade. No entanto, diante da expectativa, expressa pel os participantes, de obter medicamentos de forma rápida, a farmácia parece satisfazer as suas necessidades: Farmácia não tem essa nem aquela, pro cara dizêassim, pro cara chegá edizêassim, eu tô sentindo isso e el es não passá remédio. Só que eu nunca fui, mas eles passam. Seelestão lá pra vendê, élógico que eles vão passa um remédio. (Sérgio)
Eles falam qualquer coisa: "Pô, leva esse aqui que isso aqui é melhor". Aí você chega, toma 0 remédio, o remédio não funciona, vocêvolta ecompra outro. Ele tá ganhando comissão. (Ailton)

Cê chega lá, o que quiser comprar eles te vendem, não querem nem sabê. M as informação eorientação énenhuma mesmo. Raramente, raramente, mesmo, você encontra um balconista, um farmacêutico que queira dar uma orientação. (Rose)

Parece haver, no entanto, na percepção de alguns participantes, uma diferenciação na qualidade do atendimento recebido nas farmácias com manipulação, como também nas farmácias maiores: Porque, tipo assim, em farmácia homeopática você tem um tratamento muito bom. Eles são muito corretos, eles explicam. Se eles têm dúvida, eles pegam o telefone da médica. A gora, em drogaria, em geral, não. (Flávio)

\section{O papel central dos medicamentos}

Outra constatação importante que deve ser considerada, por influenciar, diretamente, o consumo de medicamentos e se manifestar na atitude das pessoas que buscam tratamento em farmácias e nas práticas dos trabal hadores que buscam atender a essas expectativas, foi o papel central ocupado pelo medicamento como solução para os problemas de saúde, a percepção de que toda doença exige um tratamento farmacológico. Outros autores brasileiros já demonstraram o fenômeno cultural da supervalorização das terapias medicamentosas, com o medicamento simbolizando a esperança de cura para todos os males, inclusive os causados pela precariedade das condições de vida, ou mesmo, para resolver problemas decorrentes de hábitos inadequados ou estados fisiológicos $3,9,11,18$.

Os medicamentos foram transformados pela lógica do mercado epela concepção reducionista de saúde e doença em instrumento central das práticas de saúde e essenciais para o seu exercício. Essa visão contribui para transformação da saúde em mercadoria e os medicamentos e as tecnologias associadas passam a ser fins neles mesmos, ganhando crescente autonomia, o que diminui a importância dos indivíduos no processo de cura9. A atitude dos prescritores pode reforçar esse papel central do medicamento, quando apresentam a receita ao paciente, como resultado e objeto mais valorizado no processo de assistência. Essa centralidade pode sugerir uma delegação de efetividade das ações do profissional para o medicamento e uma transposição das expectativas do paciente, quetransfereseu desejo 
de um atendimento humanizado para um medicamento eficaz. 0 tipo de atendimento, superficial, que relatam receber parece moldar suas expectativas ${ }^{11}$.

Verificou-sea insatisfação com o atendimento médico que não resulta em prescrição. Em geral, os consumidores associam a qualidade do profissional à sua predisposição em prescrever medicamentos, principalmente os considerados modernos. Esse fato foi observado também por outros autore ${ }^{10,18}$ e nos relatos a seguir: Que eu vi acontecê até comigo. Chegar com os exames e doutô não passá nem comprimido. Desse jeito eu também sei fazê, uai. Vou voltá lá pra casa. (Beto)

Eu fiquei assim, chateado. Porque depois dos exames tudo feito, só o médico, sabe? Vê, analisá e me entregá o remédio certo pra mim tomá, então, ele não. (Batista)

A penas um participante mostrou outra percepção do medicamento, como instrumento de tratamento e cura não isento de riscos. Esse relato veio do participantemais idoso do grupo: Eu não gosto deremédio, só tomo nasúltimas. Conhe ci um amigo meu, ele tá tomando oito tipo de remédio: um pra diabete, um pra colesterol, outro pra circulação e outro pra combatê o gastrite, que o que ele tá tomando é muito forte. (Beto)

Estudos antropológicos citados por Soares ${ }^{10}$ sobre as percepções e representações do medicamento evidenciam visões contraditórias, como substâncias que podem libertar de um mal-estar ou doença, mas que podem também aprisionar ou tornar dependente. Os medicamentos são vistos, ao mesmo tempo, como mercadorias ou substâncias químicas, com poder de cura e alto valor simbólico. Eles podem devolver a saúde, mas podem, por outro lado, representar a perpetuação da doença. Podem tanto representar a atenção como serem considerados uma alternativa do paciente para a falta de cuidado. Podem, ainda, ser considerado o resultado de um dado conhecimento, a prova concreta de um diagnóstico, como também a tentativa de ensaio e erro, para um problema desconhecido.

Apesar do papel central que o medicamento ocupa nas expectativas dos pacientes, esta pesquisa e outras realizadas no sistema público constataram que, embora a expectativa principal seja a prescrição de um medicamento, eles também anseiam por um atendimento atencioso, al guém com quem possam falar, que os toque, que se importe com o seu sofrimento eque semostreinteressado em solucionar o seu problema de saúde ${ }^{10}$.

Observa-se, também, em várias ocorrências, que pelo tipo de atendimento que o paciente re- cebe nas unidades de saúde públicas, não há, segundo a sua percepção e expectativas, diferença com 0 atendimento feito por farmacêuticos. Os conhecimentos e a diferente formação dos médicos não transparecem no atendimento que relatam receber. A diferença entreo preparo dos dois profissionais para o diagnóstico e a definição do tratamento mais adequado também parece passar despercebida pelos usuários, possivelmente pela forma como o paciente é atendido. Entre as várias ocorrências que evidenciam essa percepção, podemos ilustrar com os seguintes relatos: Existe uma parte, o médico passa o remédio, não deu certo, se não deu certo você volta de novo, aí vai dar outro diferente. Assim também podeacontecer na farmácia. (Beto)

Se ele ol ha na sua cara e passa um remédio pra você, é a mesma coisa do farmacêutico. Qualquer um remédio que o médico passá pra você, assim só olhando, éa mesma coisa que fosse um farmacêutico. (Paulo)

$\mathrm{Na}$ análise de discurso crítica, um item importante é a verificação das percepções e a maneira como a construção das identidades pode afetar o modo como as pessoas agem na sociedade. Segundo M oita-Lopes ${ }^{19}$, os seres humanos, como usuários da linguagem, constroem a si próprios e aos outros, assim como a realidade social, por meio do discurso. As identidades sociais não estão nos indivíduos, mas emergem na interação entreos indivíduos, influenciando atitudes, comportamentos e as relações. Um aspecto que se destacou nos discursos foi a forma como os participantes constroem a identidade defarmacêuticos, balconistasemédicos por meio da linguagem. A construção da identidade de farmacêuticos mostra-se associada a de balconistas e complementar à visão das farmácias. Percebeseque os papéis são, muitas vezes, indissociáveis. Alguns participantes constroem eexpressam uma imagem da farmácia como estabelecimento de venda demedicamentos e do farmacêutico como vendedor de remédios, que objetiva apenas obter lucro com a venda de produtos. Farmacêuticose balconistas não são vistos pela maioria dos participantes como profissionais de saúde, nem como trabal hadores com diferente formação profissional; ambos são identificados pela prática devenda demedicamentosquetem como principal valor a busca do lucro: A pessoa chega lá se queixando dos problema, ele libera mesmo o remé dio, ele vende mesmo. Não interessa se aquilo vai fazer bem ou mal. (Fátima)

Raramente, raramente mesmo, você encontra um balconista, um farmacêutico que queira dar 
uma orientação. Eleacaba te vendendo aquilo, sem receita, sem nada. Aí sabeque se acontecer alguma coisa é problema seu. (Rose)

Outras queixas dizem respeito ao despreparo eà falta dequalificação e até de ética dos atendentes nas farmácias, evidenciando a percepção de risco que os usuários correm ao se dirigirem a uma farmácia: Isso é um risco que a gente corre, né? Ao chegar numa farmácia aonde tem um balconista que não é qualificado. Ele não conseguiu ler o nome do remédio, mesmo assim ele queria receitar aquele remédio.(Ronaldo)

No entanto, no decorrer das discussões, surgi ram opiniões divergentes com relação à identidade do farmacêutico como profissional de saúde. Alguns participantes demonstraram confiança no profissional farmacêutico, associando adjetivos como confiável, experiente, especializado, entre outros: Às vezes o farmacêutico antigo, uma pessoa que já trabalhou, trabalha ali na farmácia há anos, eu tenho muita confiança em farmacêutico.(Sérgio)

Eu conheço uma pessoa que tava desenganada. 0 médico mandou morrer em casa. M eu avô, como era homeopático, aplicou os remédio. A muiétá aí hoje com 39 além dos desenganado pelo médico.(Beto)

Em apenas dois depoimentos aparece de forma clara a diferenciação entre balconista e farmacêutico. 0 participantepareceintuir, também, a questão da remuneração superior do farmacêutico, inviabilizando a exigência de apenas farmacêuticos para 0 atendimento nas farmácias: Porque você não sabe se ele é farmacêutico ou balconista. Às vezes, eletem só o segundo grau, básico, e é um vendedor. $\mathrm{Na}$ farmácia, não tem como sobreviver tendo todos os balconistas farmacêuticos, o salário é alto. (Cosme)

A construção da identidade demédico foi expressa de forma ambígua e contraditória. Em várias ocorrências, observa-se a formação deuma identidade influenciada por imagens negativas, construídas pelas experiências sofridas pelos pacientes e, possivelmente, influenciada pelo discurso da mídia incorporado pelos participantes: É, mas muitos da rede pública, ele não atende você legal, porque o emprego dele tá garantido. Faz por as metade. Sabe que tem que prestá serviço noutro, porque médico não tem só um emprego.(José)

Vocêvai lá, paga tanto. Aí ele pega, atende. Aí, se tivécinquenta pessoas pra ele atendêali, durante meia hora, ele quer fazê o mais rápido possível. (Celso)

Outros expressam essa identidade, de forma negativa e irônica, pelo uso de metáforas, de- monstrando ressentimento pelo tratamento re cebido: Você pode vê: "D outô, eu vi um vulto preto aqui na minha frente, assim. Eu fiquei vendo e apareceu de noite". Ele tem que passá medicamento de qualquer jeito. (Beto)

M édico pode curá a pessoa, da primeira vez ele sabe 0 teu poblema. M as ele é igual a um rádiotécnico. Ele sabe do poblema da tel evisão, mas diz: "Eu vou levar pra lá pra abrir, porque aqui não tem jeito". M esmo assim é o médico, el e sabe o teu poblema, mas ele não dá o remédio pra combatê, queé pra voltar, pra dá retorno, pra caí a verba pra ele, seja pro hospital. (Beto)

A pesar da visão negativa expressa por alguns, observou-se a centralidade do médico como profissional de saúde. Outros profissionais, que lidam com os pacientes, não foram lembrados quando os participantes qualificavam os serviços de saúde, exceto em dois relatos nos quais foram citados os psicólogos. A pareceram também manifestações de satisfação com relação ao atendimento médico demonstradas por experiências positivas com atendimento de suas expectativas: Fui no H M IB com muita dor no pé da barriga, a médica excel ente. Então, assim, tem exceções. (Fátima)

Os médicos e os psicólogos, pelo menos pra nós que somos soropositivos, desse posto aqui, são ótimos, atenciosos, né?(Cosme)

Outros participantes atribuem a má qualidade do atendimento ao sistema de saúde, isentando a responsabilidade do médico: $E$, mas nem todos são assim. Às vezes, o médico tem até boa vontade pra conversar com você, te atendêmelhor. M as por causa daquelemonte degentequetá lá, ele às vezes não pode fazer isso. (Gilmar)

Outros aspectos importantes, a serem considerados na análise de discurso crítica, são a intertextualidadee interdiscursividade, que de forma simplificada representam uma maneira de demonstrar como outros discursos aparecem nos discursos dos partici pantes. Intertextualidadeéa propriedade que os textos apresentam de serem constituídos de fragmentos de outros textos, que podem ser explicitamente referidos ou incorporados de forma implícita. $\mathrm{Na}$ intertextualidade manifesta, outros textos ou discursos estão explicitamente presentes, manifestamente marcados ou sugeridos por traços na superfície do texto, como as aspas e citações. $\mathrm{Na}$ intertextualidade constitutiva ou interdiscursividade, entretanto, outros discursos entram na produção e na manifestação de idéias, sem que esteja explicitamente sugerido ${ }^{16}$.

Segundo Oliveira ${ }^{20}$, o sujeito aprende a ver 0 mundo pelos discursos que assimila e, na maior 
parte das vezes, reproduz seus conteúdos em sua fala. Seu dizer éreprodução inconsciente do dizer do grupo social ao qual pertence, daí por que não se dá conta de suas vinculações, atribuindo a si próprio a constituição do sentido. Deuma forma menos frequente, podem aparecer discursos divergentes quando a criatividade individual resiste aos discursos dominantes e manifesta opiniões discordantes.

A análise da intertextualidade einterdiscursividade inclui a identificação das representações significativas paras os participantes. As representações incluem as práticas de significação e os sistemas simbólicos por meio dos quais significados são produzidos e podem ser compreendidas como processo cultural, que estabelece identidades individuais e coletivas ${ }^{21}$. A mídia e as estratégias de marketing podem construir ou contribuir para a construção de novas identidades quepodem ser apropriadas, reconstruídas ou até contestadas ou preferidas relativamentea outras.

$\mathrm{Na}$ análise dos relatos colhidos nas reuniões dos GF, percebe-se em algumas ocorrências a incorporação de vários discursos, principalmente os discursos da mídia e das instituições, sendo incorporados e expressos no discurso dos participantes: É, a situação da saúde em Braślilia tá pre cária, nós sabemos disso, vêno noticiário. N o H ospital de Base, na Ceilândia principalmente, o hospital delá tá ruim de saúde, né? 0 hospital de lá tá mais doente queo paciente. A cho que devetá acontecendo alguma coisa: ou é administração ou é re curso. Então isso aí pesa pro lado de procurá tratamento em farmácia e se automedicá. (Cosme)

Acho se cêpaga imposto, cêtambém tem direito. (Flávio)

Observa-senos exemplos anteriores, o discurso da mídia, incorporado no discurso dos participantes, avaliando emostran do a situação dos serviços de saúde como “precária”, retratando as filas nos principais serviços de atendimento no Distrito Federal. 0 discurso da mídia e das instituições, mostrando a necessidadee o direito de reivindicação demelhor qualidadeno atendimento, em face dos impostos pagos pelo cidadão, apresenta-se de forma explícita no discurso dos participantes, deixando dúvidas sobre atéque ponto esta é uma experiência vivida pela pessoa que fala ou se é 0 discurso de outro falando por meio dele.

Fairclough ${ }^{16}$ destaca a ten dência de utilização de marcadores de hierarquia e assimetria de poder nos discursos nos quais as relações são desiguais, como as tomadas de turnos (interrupções nas falas), o uso de imperativos e de vocabulário inacessível a outros. Esses marcadores podem estar explícitos ou aparecerem de maneira sutil em discursos informais. A assimetria de poder entre profissionais de saúde e pacientes têm sido estudada por diferentes pesquisadores que utilizam a análise de discurso crítica. A literatura sugerequea principal forma demanifestação dessa assimetria entre profissionais de saúde e pacientes sefaz pelo uso devocabulário inacessível, forma autoritária de fazer recomendações ou pela omissão de informações e orientaçõeses 22,23 .

$\mathrm{M}$ agal hães ${ }^{22}$, ao analisar as relações de poder no discurso médico em hospital universitário, indica a necessidade de tomada de consciência sobre os direitos linguísticos da população que não fala a linguagem médica, destacando a necessidade de eliminar a discriminação linguística e todas as formas de dominação, injustiça e opressão linguística, expressas pela falta de comunicação ou pelo uso de linguagem fora do alcance do entendimento dos pacientes. Os direitos linguísticos da população relativos ao atendimento em saúde deveriam incluir os direitos das pessoas fazerem perguntas, serem ouvidas, receberem os diagnósticos com clareza, receberem todas as informações que julgarem pertinentes ao seu estado de saúde, em linguagem clara eacessível e serem tratadas de forma respeitosa e sem preconceitos.

Tal assimetria aparece em vários relatos, citados anteriormente, em que a precária qualidade da assistência recebida e a frágil relação entre profissionais de saúdee pacientes aparecem como principal justificativa para a prática da automedicação e a procura das farmácias. Alguns relatos podem exemplificar esse tipo de assimetria presentena relação médico-paciente experimentada pelos participantes: Quando eu levei os exames pra ele ver, nem deu pra perguntar nada. Ele foi desfolhando, desfol hando, ele pegou, começou a escrever. "Oh, tu vai comprar esse aqui e tal, tal". (Celso)

Cênão podenem abri a boca. Aquela coisa de boi, né? Eu fui falá com a médica, ela disse: "Não, não, eu sou formada". Eu falei: "Eu sei, mas você não é veterinária. Veterinário é que a gente leva 0 cachorro e ele não fala nada". (Flávio)

\section{Conclusões}

A metodologia qualitativa utilizada mostrou-se de grande valor ao revelar, do ponto de vista do usuário, a existência de busca de tratamento nas farmácias para problemas complexos de saúde e as motivações que levam a essa prática. Considerando-se o universo estudado nos grupos focais, 
de usuários de um serviço de referência para tratamento de DST, pôde-se observar, também, a insatisfação com a acessibilidade e com a qualidade do atendimento nos serviços de saúde, a deteriorada relação entre profissionais de saúdee pacientes e o papel central do medicamento nas práticas dos profissionais de saúde e nas expectativas dos usuários, aparecendo como principal opção para a solução dos problemas de saúde. Os hábitos de consumo dos indivíduos, as relações interpessoais dos profissionais de saúde e pacientes e as percepções e atitudes diante dos medicamentos são fenômenos culturais que podem ser utilizados como estratégia de mercado e mostram os reflexos dos determinantes estruturais do setor farmacêutico.

A investigação qualitativa mostrou, ainda, que a prática da automedicação está inserida no cotidiano dos investigados e mostra ter relação, também, com a autonomia no cuidado e no restabelecimento de um estado de saúde desejado pelo paciente, que decide quando e como fará uso de recursos terapêuticos que Ihe pareçam convenientes, fato esse relatado por outros pesquisadores brasileiros.

Os resultados sugerem a necessidade de humanização dos serviços de saúde, principalmente na rede pública, bem como a priorização no atendimento dos casos de doenças infecciosas, como forma de controle. A humanização dos serviços de saúde pode ser compreendida como o oferecimento de atendimento de qualidade ao usuário, articulando valorização profissional com boas condições de trabalho e disponibilização de recursos tecnológicos aos profissionais de saúde $e^{24}$.

Outra constatação foi a de que as farmácias aparecem como alternativa para a dificuldade de atendimento nos serviços de saúde, cumprindo o papel de fornecedoras de medicamentos, não sendo, porém, reconhecidas como local de busca para orientações sobre saúde. Esses achados corroboram as recomendações para que se estabeleçam parcerias com as farmácias, no sentido da qualificação do pessoal envolvido com a dispensação de medicamentos, de forma a contribuir para a prevenção de doenças, para a orientação quanto à adesão terapêutica e para o uso racional de medicamentos.

A identidade de farmacêuticos, confundida com a de balconistas, ou de "vendedores de re médios" constatada na pesquisa parece resultar de seu afastamento da atividade de orientação ao pacientee desua identificação com outras atividades ligadas à administração e gerência das farmácias preconizadas como as novas tendências de mercado, conforme estudos históricos da profissão ${ }^{23}$. Por outro lado, o afastamento do farmacêutico deixa um espaço ocupado pelos balconistas, queassumem responsabilidades não condizentes com suas características de formação e escolaridade. Torna-se evidente a necessidade de definição de normas ou exigências para a qualificação sistemática desses trabal hadores e limitação de suas atribuições.

Ao reconhecer-sea extensão da rede deserviços que as farmácias podem representar, o principal desafio éa sua transformação em estabelecimentos de saúde, no qual o fornecimento de medicamentos seja uma de suas funções e não a única. Os farmacêuticos podem, também, assumir grandeimportância como educadores ecomo elo entre os usuários e os serviços de saúde e contribuir, em suas atividades, para que os medicamentos não sejam usados em substituição ao enfrentamento dos determinantes sociais e ambientais das doenças. 


\section{Colaboradores}

JOS N aves trabal hou na concepção teórica, realização da pesquisa de campo, elaboração e redação final do texto; LLC Castro e E M erchán-Hamann trabalharam na orientação e condução do trabalho de campo e na elaboração e redação final do texto. CM S Carvalho trabalhou na orientação da análise de discurso e na revisão final do texto.

\section{Referências}

1. World Health Organization. International Pharmaceutical Federation. The role of the pharmacist in the fight against the HIV-AIDS pandemic. A joint declaration between the WHO and IPF. Geneva: WHO; 1997.

2. Naves JOS. Orientação farmacêutica para DST nas farmácias do DF: um estudo de intervenção [tese]. Brasília (DF): Faculdade de Ciências da Saúde, Universidade de Brasília; 2006.

3. Gir E, Duarte G, Pinto VM, Machado JP, Reis RK, Carvalho MJ. Conhecimento de balconistas de farmácia de Ribeirão Preto sobre gonorréia. J Bras Doenças Sex Transm 2003; 15(3):24-30.

4. Loyola-Filho Al, U choa E, Guerra HL, Firmo JOA, Lima-Costa M F. Prevalência e fatores associados à automedicação: resultados do projeto Bambuí. Rev. Saude Publica 2002; 36(1):140-153.

5. World Health Organization. The role of the pharmacist in self-care and self-medication. Report of the $4^{\text {th }}$ WHO Consultive Group on the role of the pharmacist. Netherlands: WH O; 1998.

6. Organização Pan-Americana da Saúde. Ministério da Saúde. Avaliação da Assistência Farmacêutica no Brasil: estrutura, processo e resultados. Brasília; OPAS/ M inistério da Saúde; 2005.

7. Castro LLC, Costa AM, Kozoroski AM, Rossini A, Cymrot R. Algumas características da prática farmacêutica da automedicação em Campo Grande. Rev Bras Ciênc Farm 2002; 21(1):4-10.

8. Brasil. Ministério da Saúde. [site da Internet] [acessado 2008 jul 07]. Disponível em: http://www. aids.gov.br/data/Pages/LU M IS8B526207PTBRIE.htm

9. Hardon A, Hodgkin C, Fresle D. How to investigate use of medicines by consumers. Switzerland: WHO/University of Amsterdam/Royal Tropical Institute; 2004.

10. Soares JCRS. A autonomia do paciente e o processo terapêutico [tese]. Rio de Janeiro (RJ): Instituto de Medicina Social, Universidade Federal do Rio de Janeiro; 2000.

11. Lefèvre $F$. A oferta e a procura de saúde através do medicamento: proposta de um campo de pesquisa. Rev. Saude Publica 1987; 21(1):121-128.

12. Debus M. El manual para excelencia en la investigación mediante grupos focales. Washington, D.C.: Academia para el Desarrollo Educativo; 1995.

13. Westphal M F, Bógus CM, Faria M M. Grupos Focais: experiências precursoras em programas educativos em saúde no Brasil. Bol Oficina Sanit Panam 1996; 120(6):472-481.

14. M arcuschi LA. Análise da conversação. São Paulo: Ática; 1986.

15. M inayo MCS. 0 desafio do conhecimento. Pesquisa qualitativa em saúde. $3^{\text {a }}$ ed. São Paulo: Hucitec; Rio de Janeiro: Abrasco; 1994.

16. Fairclough N. Discurso e mudança social. Brasília: Editora UnB; 2001.

17. Villarino A, Soares IC, Silveira CM, Rödel APP, Bortoli R, Lemos RR. Perfil da automedicação em município do Sul do Brasil. Rev. Saude Publica 1998; 32(1):43-49.

18. Zackiewics C. Investigação das práticas de automedicação em pacientes crônicos sob terapia medicamentosa [dissertação]. Rio de Janeiro (RJ): Escola Nacional de Saúde Pública, Departamento de Ciências Sociais; 2003. 
19. Moita-Lopes LP. Identidades fragmentadas. Campinas: Mercados das Letras; 2002.

20. Oliveira SRM . Ideologia e linguagem: a natureza social da linguagem. Cad Linguagem Sociedade 1997; $3(1): 9-19$.

21. Dooley RA, Levinsohn SH. Análise do discurso: conceitos básicos em linguística. Petrópolis: Vozes; 2003.

22. Magalhães I. Eu e Tu: a constituição do sujeito no discurso médico. Brasília: Thesaurus; 2000.

23. Organização Pan-Americana da Saúde. Conselho Federal de Farmácia. 0 papel do farmacêutico no sistema de atenção à saúde. Brasília: OPAS; 2004.

24. Deslandes SE. Análise do discurso oficial sobre humanização da assistência hospitalar. Cien Saude Colet 2004; 9(1):7-14.

Artigo apresentado em 29/07/2008

Aprovado em 01/09/2008 